\title{
A CULTURA E A SOCIEDADE MANAUARA EM DOIS IRMÃOS, DE MILTON HATOUM: O CONTEXTO DESPRIVILEGIADO DE DOMINGAS
}

\author{
Gisele Cristina Kraeski ${ }^{1}$ \\ Antonio Aparecido Mantovani ${ }^{2}$
}

\begin{abstract}
RESUMO
Compreender o significado simbólico da obra literária consiste em analisar os diversos elementos presentes em contexto. A obra Dois irmãos, de Milton Hatoum, é permeada por esses elementos, que nos ajudam a entender a sociedade manauara em seu processo de formação. Assim, por meio deste artigo, busca-se analisar, no contexto da obra e da época descrita, a personagem Domingas, vista como indígena aculturada que ocupa uma posição servil em relação aos demais personagens, e que tem sua identidade desconstruída, à medida que se insere nessa situação de servidão. Baseando-nos no trabalho de Rama e Candido, utilizamos pesquisadores da obra de Hatoum, como Mantovani, Alves e Borges. Pudemos concluir que a obra de Milton Hatoum nos apresenta elementos de reflexão sobre a vida, sobre os conflitos sociais e sobre a cultura das populações desprivilegiadas da Amazônia brasileira no seu processo de formação.
\end{abstract}

Palavras-chave: Literatura brasileira. Milton Hatoum. Dois irmãos. Domingas.

\begin{abstract}
Understanding the symbolic meaning of the literary work consists of analyzing the various elements present in context. Milton Hatoum's work Two Brothers is permeated by these elements, which help us to understand the manauara society in its formation process. Through this work, we seek to analyze, in the context of the work and the time described, the personage Domingas, seen like native acculturated and that occupies a servile position in relation to the other personages, and which has its identity deconstructed, as it is inserted in this situation of servitude. Building on the work of Rama and Candido, we use researchers from the work of Hatoum, as Mantovani, Alves and Borges. We could conclude that the work of Milton Hatoum presents us with reflections on life, social conflicts and the culture of the underprivileged populations of the Brazilian Amazon in its formation process.
\end{abstract}

Key-words: Brazilian literature. Milton Hatoum. Two Brothers. Domingas.

\section{INTRODUÇÃO}

Dois irmãos, de Milton Hatoum, é uma consagrada obra da literatura brasileira contemporânea. Com traduções em diversos países, a obra resgata uma narrativa familiar, memorialística, que centraliza a temática do conflito entre irmãos, um contexto que remonta das narrativas religiosas e causa impacto. Sua narrativa é construída através do olhar do narrador personagem Nael para o passado das pessoas com quem convivia, sua pretensa

\footnotetext{
1 Mestranda no PPGLetras, Estudos Literários da Universidade do Estado de Mato Grosso.

2 Graduado em Letras pela UNEPAR - PR. Especialista em Literatura Brasileira pela Universidade Católica de Minas Gerais - PUC/BH. Mestre e Doutor em Estudos Comparados de Literaturas de Língua Portuguesa pela Universidade de São Paulo - USP. Professor do Curso de Letras do Campus da UNEMAT de Sinop, e membro permanente dos Programas de Mestrado em Letras PROFLETRAS e PPGLetras. E-mail: amantovani@unemat.br
} 
"família", tornando o foco narrativo externo, longínquo (pois remete a um tempo passado), porém, interno no tocante ao conhecimento dos fatos e conflitos presentes na história narrada.

Segundo Mantovani (2009, p. 31), o "espaço da ficção de Milton Hatoum nos remete à construção imaginária da cidade de Manaus e suas transformações, não apenas do ponto de vista material, mas, sobretudo, simbólico". A construção dos espaços se dá, portanto, de forma a resgatar não apenas o conflito familiar, mas, principalmente, a formação da cidade de Manaus e a expansão da região amazônica. Assim, este trabalho objetiva analisar a construção da cidade de Manaus, social e culturalmente, com foco na análise da personagem Domingas, índia criada da casa e mãe do narrador personagem. Os principais autores mencionados são Candido e Rama, sobre literatura e cultura, e pesquisadores da obra de Hatoum: Mantovani, Alves e Borges, entre outros.

\section{DOIS IRMÃOS, DE MILTON HATOUM - A HISTÓRIA}

Segundo Cristiane de Mesquita Alves (2017, p. 22), em sua dissertação publicada posteriormente sob o título $A$ voz do narrador e da personagem através da memória em Machado de Assis e Milton Hatoum, o "ato de narrar está intrinsecamente relacionado ao ato de recordar, costurar fios do tecido da vida envelhecidos que necessitam ser revisitados para dar continuidade ao tempo que se vive no presente". Essa revisitação é perceptível na narrativa de Dois irmãos (2000), em que Milton Hatoum nos apresenta, pela voz do narrador personagem Nael, a história de dois irmãos gêmeos que apresentam personalidades absurdamente diferentes, em um ambiente de conflito familiar e social, na perspectiva de Manaus em processo de urbanização e modernização. Contada a partir da ótica de um narrador personagem que busca sua identidade e seu passado por meio da procura pela figura paterna entre os irmãos Omar e Yakub, a história vai sendo contada "ao longo das lembranças da narração de Nael, apenas por meio das ideias memorialísticas dele" (ALVES, 2017, p. 57).

É por meio de Nael que tomamos conhecimento das desavenças familiares e passamos a desconfiar, até mesmo investigar sua possível paternidade entre os gêmeos (ou como diriam as maledicentes línguas da vizinhança, filho do próprio Halim, pai dos gêmeos).

Segundo Brait (1985, p. 65), "a personagem-narrador funciona como a lente privilegiada através da qual o leitor recebe e visualiza as personagens". Assim, "vemos tudo através da perspectiva da personagem, que, arcando com a tarefa de 'conhecer-se' e expressar esse conhecimento, conduz os traços e os atributos que a presentificam e presentificam as demais personagens" (BRAIT, 1985, p. 62). Yakub e Omar são apresentados de forma oposta, mesmo que "juntos, pareciam a mesma pessoa" (HATOUM, 2000, p. 20). Essa semelhança 
física e absurda diferença comportamental, também são destacadas quando a irmã, ao descartar todos os pretendentes, é vista pelo narrador como desejosa de unir os dois irmãos em um homem para lhe fazer par: "Observa o meu irmão Omar; agora olha bem para a fotografia do meu querido Yakub. Mistura os dois, e da mistura sairá o meu noivo" (HATOUM, 2000, p. 73). Podemos perceber que o narrador realiza uma observação profunda e íntima de Rânia, como se pudesse ler seus pensamentos mais obscuros.

Narrada após o fim dos acontecimentos, a história, por um lado "permite ao narrador fazer uma análise das demais personagens, por outro impregna essa análise dos seus desejos" (MANTOVANI, 2009, p. 94). É perceptível a ânsia do narrador de que seu pai fosse o gêmeo Yakub, com o qual se identifica e percebe um carinho por sua mãe. O narrador admira-o com paixão.

Perguntei à minha mãe o que eles tinham conversado quando ele entrou no quarto dela. O que havia entre os dois? Tive coragem de lhe perguntar se Yakub era o meu pai. Eu não suportava o Caçula, tudo o que via e sentia, tudo o que Halim havia me contado bastava para me fazer detestar o Omar (HATOUM, 2000, p. 152).

Porém, a revelação de sua verdadeira origem, que o narrador só faz ao final da história, pode ser facilmente notada pelo asco apresentado por Nael quando se refere ao personagem Omar, e quando dá destaque às falas do pai dos gêmeos, Halim, que também apresenta uma imagem negativa do filho caçula.

O marco inicial da briga entre os irmãos é a busca pela atenção da jovem Lívia, que posteriormente casa-se com Yakub. Na ocasião dessa briga, o adolescente Yakub é ferido no rosto e, mesmo vítima, é enviado ao Líbano, enquanto Omar é mantido no seio familiar. A história é permeada pela expectativa de tragédia: "O duelo entre os gêmeos era uma centelha que prometia explodir" (HATOUM, 2000, p. 46). Já próximo do fim da narrativa, Zana envia uma carta "a Yakub em mais uma tentativa de aproximar os filhos na construção de um hotel" (MANTOVANI, 2009, p. 107). Omar, no entanto, ao descobrir a participação do irmão na empreitada que estava envolvido, revolta-se, dando vazão ao confronto decisivo e final entre os irmãos:

\footnotetext{
Quando gritei, Omar deu um salto, ergueu a rede e começou a socar Yakub no rosto, nas costas, no corpo todo. Corri para cima do Caçula, tentando segurá-lo. Ele chutava e esmurrava o irmão, xingando-o de traidor, de covarde. (...) Com um gesto brusco eu agarrei a mão de Omar. Ele conseguiu se livrar de mim. (...) Ainda o vi correr até a sala e rasgar com fúria as folhas do projeto; rasgou todos os desenhos, jogou a louça no assoalho e desabalou pelo corredor (HATOUM, 2000, p. 175).
}

A narrativa se encerra com a degradação total da família e do ambiente. Segundo Mantovani (2009, p. 137), a casa é destruída e o "final do romance não oferece saída, tudo se perdeu. Restaram apenas ruínas e silêncio". Cabe ao narrador, remanescente dessa família 
desmantelada, juntar as migalhas e restos na busca de encontrar-se.

\section{A FORMAÇÃO DE MANAUS NO CONTEXTO DA OBRA}

A obra Dois irmãos se passa em Manaus e remete à formação da cidade, dando destaque a vários acontecimentos, como a vinda de estrangeiros para a região - "Manaus cresceu assim: no tumulto de quem chega primeiro" (HATOUM, 2000, p. 32) -; o Ciclo da Borracha - "Vendia de tudo um pouco aos moradores dos Educandos, um dos bairros mais populosos de Manaus, que crescera muito com a chegada dos soldados da borracha, vindos dos rios mais distantes da Amazônia" (HATOUM, 2000, p. 32) -; a ditadura militar - "O pai reclamava que a cidade estava inundada, que havia correria e confusão no centro, que a Cidade Flutuante estava cercada por militares" (HATOUM, 2000, p. 147).

\footnotetext{
Esse período histórico que perpassa o romance é o fim do Ciclo da Borracha, a Segunda Guerra Mundial, o processo de modernização tardia que o país experenciou especialmente em São Paulo, sendo que em Manaus essa modernidade nem conseguiu chegar como é constatado na obra e, por fim, termina com a tomada da cidade pela Ditadura Militar com o Golpe de 1964, que contribuiu na criação da Zona Franca de Manaus, período que colaborou para transfigurar mais ainda a cidade (BORGES, 2010, p. 34).
}

O romance nos apresenta a busca pelas origens não apenas do personagem-narrador, mas também do ambiente em que ele está inserido: "Eu não sabia nada de mim, como vim ao mundo, de onde tinha vindo. A origem: as origens. Meu passado, de alguma forma palpitando na vida dos meus antepassados, nada disso eu sabia" (HATOUM, 2000, p. 54). O passado de Manaus está ligado à expansão da região amazônica por ordem de Marquês de Pombal, que via na exploração da região uma forma de enriquecer Portugal (BORGES, 2010). Com o início do Ciclo da Borracha Manaus expandiu-se e o enriquecimento por meio do "ouro branco", segundo Borges (2010), foi uma das principais causas da vinda dos estrangeiros, especialmente comerciantes, para a região.

A ditadura militar não aparece na obra de forma direta, mas através dos acontecimentos, envolvendo o professor Laval e das datas envolvendo essas ocorrências: "Na primeira semana de janeiro de 1964 Antenor Laval passou em casa" (HATOUM, 2000, p. 139). A narrativa, então, apresenta fragmentos em que o professor vai aos poucos se deteriorando, até que, numa manhã de abril, Laval é preso: "A vaia e os protestos de estudantes e professores do liceu não intimidaram os policiais. (...) dois dias depois soubemos que Antenor Laval estava morto" (HATOUM, 2000, p. 142). A morte súbita e silenciosa do personagem, no obscuro dessa prisão, representa uma dura crítica aos métodos utilizados 
pelos militares para calar as vozes contrárias ao governo militar.

Quanto ao aspecto da formação de Manaus, destaca-se que a chegada repentina de pessoas de diversas culturas e nacionalidades, se deu tendo em vista o aparente desenvolvimento e futura modernização da cidade.

\begin{abstract}
Ilhada pelo rio Negro e pela floresta amazônica, Manaus tornou-se um importante centro do Norte do país e teve seu auge (belle époque) no ciclo da borracha, quando recebeu uma leva de ribeirinhos (indígenas que tentavam sobreviver na cidade), de imigrantes estrangeiros e migrantes de outras regiões brasileiras em busca de riqueza. A chegada dos libaneses à Amazônia iniciou-se na primeira década do século vinte (MANTOVANI, 2009, p. 58).
\end{abstract}

Para Pimentel Pinto Junior (2010, p. 315), a "concepção de uma nova ordem cultural resultante do confronto entre grupos sociais distintos deve muito aos percursos da História". Por meio do contato entre culturas diferentes, sofremos processos constantes de mudanças, já que "tempo, espaço, condições de produção e experiências reordenam elementos essenciais das raízes dos indivíduos, fragmentados por deslocamentos, para dar suporte à apreensão de realidades conflitantes em busca de uma identidade renovada" (PIMENTEL PINTO JUNIOR, 2010, p. 315).

Esse encontro de culturas não se daria apenas no convívio, mas na alteração dos aspectos individuais e coletivos de um povo: o manauara. "A transculturação é o processo de desarraigamento de culturas tradicionais para a formação de outra" (AGUIAR e VASCONCELOS, 2001, p. 23), o que podemos encontrar quando tratamos da vinda definitiva de imigrantes para a região amazônica ou de migrantes de outras regiões do país, vindo em busca de um "sonho dourado" de prosperidade e riqueza. O processo de transculturação descrito por Rama e proposto por Ortiz (AGUIAR e VASCONCELOS, 2001, p. 23), se opõe a aculturação (simples absorção residual de uma cultura por outra), pela "criatividade explicitada em uma dialética em que o resultado exprime e, ao mesmo tempo, supera os pontos de partida". Através do processo de transculturação, o contato entre culturas diferentes resulta num novo modo de vida, no caso a cultura manauara, híbrida e fronteiriça.

Desse modo, Hatoum interroga e desestabiliza os discursos de identidade nacional, pondo-os dentro de uma tradição literária e intelectual. Ele reescreve e redefine a própria noção de identidade cultural amazônica. O que seria o sujeito amazônico? Poderíamos definir a Amazônia de maneira coesa, harmoniosa e uniforme? São essas questões que Hatoum suscita e nos coloca a pensar. De antemão, podemos anunciar que o sujeito amazônico é o sujeito fronteiriço, híbrido que se reelabora nas negociações. A Amazônia é o espaço da confluência de saberes, identidades e culturas hifenizadas, e tentar defini-la como espaço coerente e equilibrado é, no mínimo, desconsiderar os percursos históricos entre diferentes pessoas, tempos e objetos que a constituem (PENALVA, 2015, p. 55). 
Euclides da Cunha, em À margem da história, publicada após sua morte em 1909, destaca a rudeza dos trabalhadores amazônicos da seringa, vindos do Nordeste para os maus tratos da floresta amazônica: "O sertanejo emigrante realiza, ali, uma anomalia sobre a qual nunca é demasiado insistir: é o homem que trabalha para escravizar-se" (CUNHA, 1909, p. 21). Apesar disso, Euclides destaca que a "Amazônia selvagem sempre teve o dom de impressionar a civilização distante" (p. 7), e esse encantamento trouxe imigrantes de diversas partes do mundo: "Manaus está cheia de estrangeiros, mama. Indianos, coreanos, chineses... O centro virou um formigueiro" (HATOUM, 2000, p, 167).

A expansão e posterior decadência da região amazônica deixou sequelas muito maiores na população desfavorecida. Na obra Simá - romance histórico do Alto Amazonas, de 1857, Lourenço da Silva Araújo Amazonas já observava que quando "o palácio do Magnate em sua queda esmaga a cabana do pobre, ninguém se apercebe de que o prejuízo deste pode ser maior que o daquele" (1857, p. 4). Logo, apesar da riqueza cultural apresentada na região amazônica entre os povos que aqui vieram residir, trataremos a partir de agora do impacto e perda da cultura do indígena, representada na obra Dois irmãos pela personagem Domingas, resultante de relações desiguais e servis.

\section{DOMINGAS}

De acordo com Candido (2015, p. 58), de qualquer obra que tenha "certo teor de imaginação verdadeiramente criadora, se desprende um significado que transfigura objetos e personagens". Em Dois irmãos, a personagem Domingas, "extraída de sua aldeia (ainda menina) para ser confinada num seminário e posteriormente 'vendida' a Zana" (MANTOVANI, 2009, p. 116), se apresenta como uma índia destituída de sua cultura por um processo que permeia a religiosidade cristã e o acaso da separação da família pela morte do pai.

\footnotetext{
A mãe dela... Domingas não se lembrava, mas o pai dizia: tua mãe nasceu em Santa Isabel, era bonita, dava risadas alegres, nas festas do ajuri e nas noites dançantes era a mais bonita de todas. Um dia, bem cedinho, o pai saiu para cortar piaçaba e colher castanha. Era junho, véspera de São João (...) 'Corri pra dentro da tapera, onde meu irmão brincava. Fiquei ali, arrepiada de medo chorando... Esperei meu pai... ele demorou... Ninguém sabia de nada' (HATOUM, 2000, p. 55).
}

Na cena acima descrita, Domingas se assusta com a morte de um porco-do-mato e a sensação de medo se mistura à espera do pai que não chega. "O pai tinha sido encontrado morto num piaçabal. Ainda se lembrava do rosto dele, do enterro no pequeno cemitério, na 
outra margem do Jurubaxi”" (HATOUM, 2000, p. 55).

Domingas é uma personagem secundária da trama de Dois irmãos, que pode ser considerada uma personagem estereótipo, pois representa "uma cristalização máxima dos lugares-comuns e dos valores socialmente atribuídos às diversas categorias sociais" (FRANCO JUNIOR, 2009, p. 39). Ela representa o personagem indígena que, em confronto com a cultura emancipatória da região de Manaus, assume um lugar (servil), uma cultura (a do silêncio), uma religião (a cristã) e todas essas características são assumidas a partir do contato com o homem branco colonizador. Apesar disso, "Domingas celebrava seus cultos nos igarapés e sob as copas das árvores" (PIMENTEL PINTO JUNIOR, 2010, p. 319), porém, como a passagem acima revela, desde o povoado onde morava com o pai e o irmão, ela já estava em contato com as festas católicas, como no caso a festa de São João: “a canoa com a imagem do santo se aproximava do rio, os gambeiros batiam tambor, cantavam e pediam esmola para São João. O povoado de Jurubaxi já se animava com festas e danças" (HATOUM, 2000, p. 55).

Após a morte do pai, Domingas foi levada para um orfanato de irmãs religiosas "das missões de Santa Isabel do rio Negro", do qual relata lembranças terríveis, pois "ai de quem esquecesse de uma reza, do nome de uma santa" (p. 55).

\footnotetext{
Uns dois anos ali, aprendendo a ler e a escrever, rezando de manhãzinha e ao anoitecer, limpando banheiros e o refeitório, costurando e bordando para as quermesses das missões. As noites eram mais tristes (...); às oito a irmã Damasceno abria a porta, atravessava o dormitório, rondava as camas, parava perto de cada menina. $\mathrm{O}$ corpo da religiosa crescia, uma palmatória balançava na mão dela. (...) Chorava quando se lembrava do pai, dos bichinhos de madeira que fazia para ela, das cantigas que cantava para os filhos. E chorava de raiva. Nunca mais ia ver $o$ irmão (HATOUM, 2000, p. 55-56).
}

Quando Domingas "não aguentava mais", com seus pensamentos numa possível fuga, que as irmãs diziam que seria castigada por Deus, recebeu a ordem: "Tinha que ficar limpa e cheirosa" (HATOUM, 2000, p. 56). Domingas foi levada então para a casa de Halim e Zana, jovem casal sem filhos, em troca de mesas e cadeiras de madeira e, é claro, "um envelope" que Zana "entregou à religiosa".

"Na casa da Zana o trabalho era parecido, mais tinha mais liberdade... Rezava quando queria, podia falar, discordar, e tinha o canto dela" (HATOUM, 2000, p. 57). Viu os gêmeos nascerem e cuidou de Yakub, enquanto Zana dedicava sua atenção ao caçula Omar, que nascera com a saúde fragilizada. Domingas presenciou e mesmo relatou muitos dos acontecimentos narrados por seu filho Nae: A relação entre os gêmeos, as personalidades tão diferentes, as aventuras de Omar, as conquistas de Yakub. Apesar disso, o relato mais 
importante só veio muito perto de sua morte, quando revelou a Nael as verdadeiras (porém contraditórias) condições de sua concepção.

Ficou calada por uns minutos, até a claridade sumir de vez. 'Quando tu nasceste', ela disse, 'seu Halim me ajudou, não quis me tirar da casa... Me prometeu que ias estudar. Tu eras neto dele, não ia te deixar na rua. Ele foi ao teu batismo, só ele me acompanhou. E ainda me pediu para escolher teu nome.' (...) Murmurou que gostava tanto de Yakub... (...) Omar ficava enciumado quando via os dois juntos, no quarto, logo que o irmão voltou do Líbano. 'Com o Omar eu não queria...Uma noite ele entrou no meu quarto, fazendo aquela algazarra, bêbado, abrutalhado... Ele me agarrou com força de homem. Nunca me pediu perdão' (HATOUM, 2000, p. 180).

A certeza da relação proximal entre Domingas e Yakub e a confissão do estupro sofrido pelo outro irmão causam dor, porém, percebemos ao longo da história que em nenhum momento existe um confronto por parte de Domingas, nem mesmo pela condição do filho, que é parte da família a qual ela serve. Nael é criado como empregado e filho da doméstica. Existe por parte de Domingas uma ausência de raiva, apenas mágoa e, em diversas passagens, ela socorre e cuida de Omar nos momentos de bebedeira, sem se revoltar com a violência sofrida no passado. Utiliza-se, inclusive, de seus conhecimentos fitoterápicos para ajudar o filho caçula de Zana.

Seu silêncio, apresentado ao longo da narrativa e quebrado em poucos momentos, é quase palpável pela sensação de afastamento que sentimos por parte do narrador para com sua mãe. Apesar desse afastamento, percebemos que "Domingas foi uma boa mãe e o narrador em suas rememorações não esconde a indignação que tinha em vê-la sempre explorada domesticamente pela família" (ALVES, 2017, p. 68).

Mesmo sem demonstrar a indignação que esperamos, justamente porque procuramos encontrar semelhanças entre um personagem e a pessoa humana (FRANCO JUNIOR, 2009), podemos destacar que Domingas concentrava sua raiva no orfanato, onde morou após a morte do pai, e nas irmãs religiosas do lugar, pois "detestava o orfanato e nunca visitou as Irmãzinhas de Jesus. Chamavam-na de ingrata, mal-agradecida, mas ela queria distância das religiosas, nem passava pela rua do orfanato. A visão do edifício a oprimia" (HATOUM, 2000, p. 57).

Segundo Rama, os "processos de aculturação são tão velhos quanto a história dos contatos entre sociedades humanas diferentes e sob diversos nomes têm sido estudados nos principais modelos das antigas culturas" (RAMA, 2001, p. 258). Em Domingas, essa absorção de uma cultura por outra se deu pelas relações de servidão e obediência que a enclausuraram durante o período em que esteve no orfanato das irmãs religiosas. Enquanto esteve nesse ambiente de servidão e violência, Domingas era desejosa de liberdade, queria fugir, voltar 
para seu povoado, "O meu lugar', lembrou Domingas" (HATOUM, 2000, p. 55), porém ao ser entregue à Zana, seu desejo de liberdade foi sendo sufocado, silenciado e acabou por extinguir-se com o nascimento do filho e a promessa de cuidado para com essa criança que pertencia à família.

Podemos afirmar que, conforme Rama (2001), ao incorporar os conceitos propostos por Fernando Ortiz sobre a transculturação, Domingas sofre uma "parcial desaculturação", posteriormente, incorporando "procedentes da cultura externa" e, finalmente, esforçando-se para se recompor, "ao lidar com os elementos sobreviventes da cultura original e os que vêm de fora" (RAMA, 2001, p. 264), assim como ocorreu com a cidade de Manaus e a cultura manauara, que recebeu indivíduos de várias culturas e nacionalidades diferentes, mas acabou por se reconstruir com vista nessas relações. Em Domingas essa reconstrução não foi favorável para a personagem, que acaba por se enclausurar no silêncio e no conformismo de uma vida melhor para o filho e no contexto de servidão.

Um episódio em que fica claro que Domingas perdeu sua essência cultural e identitária é quando, pedindo um domingo de folga para Zana, faz uma viagem com o filho: "Foi a única vez que saí de Manaus com minha mãe" (HATOUM, 2000, p. 54). Inicialmente, Domingas se mostra animada para rever "o lugar onde nascera, perto do povoado de São João, na margem do Jurubaxi, braço do Negro, muito longe dali" (p. 55).

\footnotetext{
Quando desembarcamos na vilinha à margem do Acajatuba, minha mãe mudou de feição. Não sei o que a fez tão sombria. Talvez uma cena do lugar, ou alguma coisa daquela vila, algo que the era penoso ver ou sentir. Não quis assistir ao casamento, muito menos esperar a festa, o foguetório, a peixada ao ar livre na beira do rio. Minha mãe tinha medo de chegar tarde em Manaus. Ou, quem sabe, medo de ficar ali para sempre, sôfrega, enredada em suas lembranças. Voltamos no mesmo motor (HATOUM, 2000, p. 57).
}

O relato dessa volta é nauseante, considerando que devido a uma grande tempestade, Domingas, Nael e todos os passageiros da embarcação foram acometidos de vômitos, gritaria e desespero com o sacolejar do barco carregado de animais. "Ninguém entendia mais nada, a gritaria se misturava com grunhidos e cacarejos (...). Chegamos de noitinha, quando ainda chovia muito. (...) O nosso estado era lamentável, estávamos ensopados, sujos, cheirando a vômito" (HATOUM, 2000, p. 58). Domingas não consegue permanecer no lugar em que nascera. Sua volta "no mesmo motor" demonstra que aquele ambiente já não lhe dizia mais nada, apenas lembranças de um tempo esquecido, distante. 


\section{CONSIDERAÇÕES FINAIS}

A narrativa de Milton Hatoum tem o poder de nos fazer pensar. Lemos, penetra no universo ficcional e imaginário, porém, o que fica é uma reflexão acerca do que o autor quis nos dizer, pois uma incógnita, uma grande dúvida nos faz perpassar a história em busca de significados. Esses significados nos dizem muito sobre o lugar, sobre o contexto histórico narrado, mas também sobre a vida humana em constante mudança.

A construção dos personagens remete à formação social e cultural de Manaus, seus migrantes, populações desprivilegiadas que não se beneficiam com o progresso planejado para a cidade. Domingas é a parcela da população amazônica, indígena, ribeirinha, seringueira, que foi explorada em prol dessa expansão e enriquecimento da região, o elo mais fraco dessa relação desigual e injusta. Acompanhando o percurso de Domingas que vai se mostrando de forma fragmentada na narrativa de Hatoum, podemos perceber a extinção do seu desejo de liberdade, o afastamento de sua natureza social e esgotamento de sua cultura por meio das relações de servidão e obediência da órfã índia para com os sujeitos que a exploram. Domingas morre sem se rebelar. É a prova de que o ciclo servil a que pertence essa população oprimida, não se esgotará.

\section{REFERÊNCIAS}

AGUIAR, Flávio; VASCONCELOS, Sandra Guardini T. Para além de Tordesilhas: o conceito de América Latina e a obra de Ángel Rama. In: (Org.). Ángel Rama: Literatura e cultura na América Latina. São Paulo: Editora da Universidade de São Paulo, 2001.

ALVES, Cristiane de Mesquita. A voz do narrador e da personagem através da memória em Machado de Assis e Milton Hatoum. 1. ed. Jundiaí: Paco, 2017.

AMAZONAS, Lourenço da Silva Araújo. Simá: romance histórico do Alto Amazonas. 1857. Disponível

$<$ http://objdigital.bn.br/acervo_digital/div_obrasraras/or1328753/or1328753.pdf $>$ Acesso em: 06 jan. 2019.

BORGES, Kárita Aparecida de Paula. Dois irmãos de Milton Hatoum: um olhar que vem do norte. 2010. 106 f. Dissertação (Mestrado em Literatura)-Instituto de Letras, Universidade de Brasília, Brasília, 2010.

BRAIT, Beth. A personagem. São Paulo: Ática, 1985.

CANDIDO, Antonio. Degradação do espaço. In: de Janeiro: Ouro sobre Azul, 2015. p. 49-82. 
CUNHA, Euclides. À margem da história. São Paulo: Coletivo Euclidiano, 1909.

FRANCO JUNIOR, Arnaldo. Operadores de leitura da narrativa. In: BONNICI, Thomas; ZOLIN, Lúcia Osana (Org.). Teoria literária: abordagens históricas e tendências contemporâneas. 3. ed. Maringá: Eduem, 2009.

HATOUM, Milton. Dois irmãos. São Paulo: Companhia das Letras, 2000.

MANTOVANI, Antonio Aparecido. Espaço em ruínas: meio social, conflito familiar e a casa em ruínas em Os dois irmãos de Germano Almeida e Dois irmãos de Milton Hatoum. 2009. 179 f. Tese (Doutorado em Letras)-Faculdade de Filosofia, Letras e Ciências Humanas, Universidade de São Paulo, São Paulo, 2009.

PENALVA, Lorena de Carvalho. Hibridismo cultural na Amazônia brasileira: um estudo do romance Cinzas do norte, de Milton Hatoum. 2015. 117 f. Dissertação (Mestrado em Teoria da Literatura e Literatura Comparada)-Faculdade de Letras, Universidade Federal de Minas Gerais, Belo Horizonte, 2015. Disponível em: $<$ http://www.bibliotecadigital.ufmg.br/dspace/bitstream/handle/1843/ECAP9VTKAG/lorena_dissert.pdf?sequence=1>. Acesso em: 25 nov. 2018.

PIMENTEL PINTO JUNIOR, Antonio Carlos. Marcas da transculturação na obra "Dois irmãos", de Milton Hatoum. Travessias, Cascavel, v. 4, n.2, p. 313-326, 2010. Disponível em: $<$ http://e-revista.unioeste.br/index.php/travessias/article/view/4167/3236>. Acesso em: 20 nov. 2018.

RAMA, Ángel. Literatura e Cultura. In: AGUIAR, Flávio; VASCONCELOS, Sandra Guardini T. (Org.). Ángel Rama: Literatura e cultura na América Latina. São Paulo: Editora da Universidade de São Paulo, 2001.p.239-280. 